\title{
O controle de mercado através da eco-eficiência e do eco-consumo: uma análise a partir dos supermercados
}

\author{
Julia S. Guivant*
}

\section{Resumo}

Neste artigo discutimos inicialmente a mudança do papel dos supermercados no sistema alimentar, que tem iniciado o que alguns autores consideram ser a sua terceira fase. Entre as diversas transformações envolvidas nesse processo destacaremos duas: a) o papel dos supermercados na conversão de consumidores em consumidores orgânicos e b) as estratégias do setor supermercadista na gestão e construção sustentável. A sustentabilidade tem passado a ser uma bandeira cada vez mais central nas estratégias do setor de supermercados, algo obviamente possível devido à imprecisão do conceito. Nossa análise se apóia fundamentalmente na teoria da modernização ecológica e de forma secundária na nova sociologia econômica dos objetos de mercado. A partir deste referencial teórico ilustramos as tendências no setor varejista nos fluxos de mercado globalizados e a influência da ação de organizações não-governamentais e grupos de consumidores. Finalmente, mostramos o mosaico complexo de tendências do setor, que exige uma perspectiva não essencialista ou dicotômica para entender como as dinâmicas e demandas ambientais passam a fazer parte não só do discurso, mas de práticas influentes destes atores econômicos poderosos e que podem passar a ter consequiências não-premeditadas nas relações entre produção e consumo nas novas regras da globalização dos mercados.

Palavras-chave: consumo sustentável, supermercados, teoria da modernização ecológica.

* Doutora em Sociologia, professora do Departamento de Sociologia e Ciência Política da Universidade Federal de Santa Catarina, coordenadora do IRIS (Instituto de Pesquisa em Riscos e Sustentabilidade), presidente da ANPPAS (Associação Nacional de Pesquisa e Pós-graduação em Ambiente e Sociedade). Endereço eletrônico: juguivant@uol.com.br. Página na Internet: www.iris.ufsc.br. 


\section{Introdução}

$\mathrm{N}^{a}$ a década de 90 o setor supermercadista passou a assumir no contexto internacional novos papeis no abastecimento de alimentos (com investimentos na área produtiva), no controle de sua qualidade, na seleção de produtos a colocar nas prateleiras. Os supermercados passaram a ser agentes centrais no processo de transformação da esfera do consumo alimentar. A capacidade dos supermercados de continuar produzindo novas opções de consumo alimentar está se fortalecendo com iniciativas cada vez mais importantes no que diz respeito às inovações e às escolhas sobre a qualidade dos alimentos. E seu poder enquanto poderosas forças corporativas transnacionais tem aumentado as criticas de diverso tipo a suas práticas concentradoras de parte de governos, organizações não-governamentais (ONGs), grupos de consumidores e produtores e também acadêmicos (LAWRENCE \& BURCH 2007).

Neste artigo discutimos inicialmente a mudança do papel dos supermercados no sistema alimentar, que tem iniciado o que alguns autores consideram ser a sua terceira fase. Entre as diversas transformações envolvidas nesse processo destacaremos duas: a) o papel dos supermercados na conversão de consumidores em consumidores orgânicos e b) as estratégias do setor supermercadista na gestão e construção sustentável. A sustentabilidade tem passado a ser uma bandeira cada vez mais central nas estratégias do setor de supermercados, algo obviamente possível devido a imprecisão do conceito. Mas, apesar desta imprecisão, como considerar as novas estratégias e quais são seus significados?

Para a análise do papel dos supermercados na conversão dos consumidores encontramos uma fonte de análise na proposta de Cochoy (2007, p.109) de uma quarta versão da Sociologia Econômica. De acordo com este pesquisador, a Sociologia Econômica desafia as explicações econômicas sobre escolhas de mercado ao propor investigar as raízes sociais, culturais e políticas dos comportamentos econômicos. Ainda que reconhecendo a relevante contribuição destas análises, Cochoy sugere que elas tendem a reduzir as realidades dos mercados a suas dimensões humanas (redes, idéias e instituições). O que teria sido negligenciado é o papel dos objetos, 
tecnologias e outros artefatos que fazem parte essencial dos mercados. A contribuição de Callon no livro de 1998, Laws of Markets, seria uma tentativa de preencher tal vácuo, de acordo com interpretação de Cochoy. A proposta deste autor é a de ampliar a perspectiva de Callon para uma sociologia dos objetos de mercado, referente a como objetos, ferramentas e enquadramentos equipam a capacidade cognitiva dos consumidores. E aqui Cochoy concentra-se em mostrar como os mercados podem ser seguidos no plano mais básico das transações comuns entre consumidores, produtos e espaços nos supermercados. Isto pode ser realizado através de uma etnografia do mercado, que Cochoy associa à metáfora do jardim. Esta metáfora "evoca solo, plantas, ferramentas e divisões espaciais, mas também marca todo o trabalho que deve ser feito para estimular o consumo" (COCHOY, 2007, p.110). A performance que tem lugar no espaço dos supermercados diz respeito a eventos bem locais e materiais, que nos estimulam a fazer 'coisas' mas também nos estimulam a pensar de forma diferente, sendo os atores em questão consumidores, produtores ou varejistas. Desde esta perspectiva, a visita aos próprios supermercados tem emergido no nosso trabalho dentro da metáfora do jardim. E isto será apresentado no item relativo ao supermercado como ponto de venda e como local para transações de alimentos sustentáveis e conversão de consumidores.

Por sua vez, a teoria da modernização ecológica (SPAARGAREN et al., 2000; 2006) nos permitirá aprofundar o entendimento das transformações ainda em processo. A noção de modernização ecológica pode ser vista como a interpretação sociológica do processo de reforma ambiental em múltiplas escalas no mundo contemporâneo. A teoria se propõe a analisar como diversas instituições e atores sociais podem integrar suas preocupações ambientais no seu cotidiano, no desenvolvimento e relacionamento com outros, incluindo aqui o mundo natural, e transcender a divisão entre ecologia e economia, internalizando os "custos externos" em funções do mercado e da economia em geral. Neste sentido, atores econômicos como o setor supermercadista não são vistos só como forças que deterioram o meio ambiente, mas como instituições de mercado que podem trabalhar em favor de uma reforma ambiental. 


\section{A terceira fase dos sistemas alimentares}

Diversos autores (BURCH \& LAWRENCE, 2005; DIXON, 2003; MCMICHAEL E FRIEDMANN, 2007) apontam a necessidade de identificar uma terceira fase, consolidada no fim dos anos 90, nos processos de transformação dos sistemas alimentares. Enquanto a primeira fase é definida como orientada pela produção, e a segunda pelo consumo, a terceira coloca o setor de supermercados como o principal condutor e tomador de decisões.

Entre os fatores apontados como principais influencias neste processo, podem ser enumerados os seguintes:

1) um número relativamente grande de companhias de processamento de alimentos é forçado a vender seus produtos a um número limitado de redes supermercadistas globalizadas que exercem um enorme poder de compra num mercado cada vez mais concentrado.

2) a crescente significação das marcas próprias dos supermercados, que passam a competir com as marcas de empresas alimentares consolidadas no mercado (BURCH \& LAWRENCE, 2005).

3) o papel central do setor na construção da qualidade, dietas, saúde e meio ambiente. As relações de poder dos supermercados em relação à indústria alimentar se legitima através de uma base de lealdade dos consumidores (MARSDEN et al., 2000).

4) o setor apresenta-se como uma autoridade no referente aos alimentos, o que lhe permite negociar a aceitação dos consumidores de novos alimentos. Dixon (2003) vai mais longe ao analisar como os supermercados se colocam como guardiões morais da soberania dos consumidores.

5) os varejistas podem substanciar sua reivindicação de ser "o mais próximo" dos consumidores de alimentos em muitos aspectos importantes por apontar o fato de que eles se encontram numa base regular, quase diária com segmentos maiores de consumidores de alimentos de tendências dominantes (SETH \& RANDALL, 2001). Os varejistas "conhecem melhor" as preocupações de seus 
clientes já que encontrá-los em suas lojas leva à informação em primeira mão sobre o que os consumidores querem e quais suas preocupações. Essas interações regulares e frequientes no ponto de venda também fornecem aos varejistas possibilidades de experimentar com novos produtos alimentares (verdes/saudáveis) e práticas. Como uma consequiência, os varejistas reclamam ter o poder de promover ou quebrar o mercado de produtos e serviços sustentáveis no setor alimentar. Eles "criam" e "controlam" não apenas consumidores verdes, mas também - "a favor do consumidor" - os fornecedores de produtos verdes (BEVAN, 2005).

6) A organização da produção e do consumo tem se tornado uma questão global e, consequientemente, cadeias de supermercados que operam no mundo inteiro têm uma posição privilegiada. Para acompanhar a alta dinâmica do consumo e produção de alimentos em mercados globalizantes - com a regulação (da qualidade) dos alimentos no "espaço de fluxos" (OOSTERVEER, 2006) - as fontes dos donos de lojas independentes, locais ou pequenas cooperativas produtores (de orgânicos) estão longe de serem suficientes. Pela concentração e internacionalização nas últimas décadas, os varejistas têm ganhado vantagem competitiva, resultando, por exemplo, no fato de que, em muitos países da Europa, as cinco maiores cadeias varejistas são responsáveis por porções consideráveis nas vendas totais de alimentos. Em 1990, não havia varejistas incluídos na lista Fortune 500 das maiores companhias globais, mas, em 2002, mais de 50 estavam na lista. Neste tempo, a Wal-Mart tinha se tornado a maior de todas as companhias, considerando o tamanho das vendas (REYNOLDS \& CUTHBERTSON, 2004, p.1-22). Este processo era relacionado ao fechamento de pequenas lojas e varejistas independentes (DOBSON et al. 2003). Em 2005, os top 10 varejistas globais de alimentos tiveram vendas combinadas de 840 bilhões de dólares - $24 \%$ do mercado global estimado em 3,5 trilhões de dólares. 
Portanto, o papel central dos supermercados deve-se à sua especial localização na rede de produtores, consumidores e processadores, o que tem levado à transformação das relações de poder no sistema alimentar tal como era conhecido antes deste fenômeno.

Quadro 1 - Regimes Alimentares

\begin{tabular}{|c|c|c|c|}
\hline & $\begin{array}{l}\text { Primeiro Regime } \\
\text { alimentar }\end{array}$ & $\begin{array}{l}\text { Segundo Regime } \\
\text { alimentar }\end{array}$ & $\begin{array}{l}\text { Ascendente terceiro } \\
\text { regime alimentar }\end{array}$ \\
\hline $\begin{array}{l}\text { Começo } \\
\text { aproximado }\end{array}$ & $1870-$ & $1950-$ & $2000-$ \\
\hline $\begin{array}{l}\text { Responsável } \\
\text { pelas decisões }\end{array}$ & \begin{tabular}{|l|} 
Estados \\
(especialmente \\
colonos) nacionais e \\
fazendeiros
\end{tabular} & $\begin{array}{l}\text { Companhia de } \\
\text { processamento }\end{array}$ & Varejista \\
\hline $\begin{array}{l}\text { Modo de } \\
\text { Regulação }\end{array}$ & Controle de estado & $\begin{array}{l}\text { Keynesianismo } \\
\text { gerenciado }\end{array}$ & $\begin{array}{l}\text { Desregulação } \\
\text { neo-liberal }\end{array}$ \\
\hline Saída & $\begin{array}{l}\text { Gêneros } \\
\text { alimentícios básicos } \\
\text { para preparação } \\
\text { caseira }\end{array}$ & $\begin{array}{l}\text { Gêneros alimentícios } \\
\text { básicos e processados } \\
\text { para preparação caseira } \\
\text { e comida fora de casa }\end{array}$ & $\begin{array}{l}\text { Gêneros alimentícios } \\
\text { básicos, processados } \\
\text { e manufaturados para } \\
\text { preparação caseira, } \\
\text { conveniência e } \\
\text { alimentação flexibilizada }\end{array}$ \\
\hline Identificador & $\begin{array}{l}\text { Produtos sem marca } \\
\text { ou não identificados }\end{array}$ & Produtos de marca & $\begin{array}{l}\text { Produtos de marca, marcas } \\
\text { do próprio supermercado, } \\
\text { marcas genéricas }\end{array}$ \\
\hline $\begin{array}{l}\text { Produção } \\
\text { alimentar }\end{array}$ & Sazonal & $\begin{array}{l}\text { Produção contínua de } \\
\text { produtos padronizados, } \\
\text { introduzidos no } \\
\text { mercado apoiados na } \\
\text { confiança da marca de } \\
\text { longa data }\end{array}$ & $\begin{array}{l}\text { Produção flexível de } \\
\text { grupos de produtos } \\
\text { diferenciados, } \\
\text { introduzidos no mercado } \\
\text { em nome do preço, } \\
\text { lealdade de varejo, } \\
\text { conveniência, novidade }\end{array}$ \\
\hline Consumidores & $\begin{array}{l}\text { Exercem pouca } \\
\text { influência }\end{array}$ & $\begin{array}{l}\text { Aceitam alimentos } \\
\text { duráveis como desejados }\end{array}$ & $\begin{array}{l}\text { Exigentes sobre a } \\
\text { qualidade e segurança dos } \\
\text { alimentos }\end{array}$ \\
\hline $\begin{array}{l}\text { Meio } \\
\text { ambiente }\end{array}$ & $\begin{array}{l}\text { Explorado e com } \\
\text { pouca preocupação } \\
\text { sobre os efeitos de } \\
\text { cultivo extensivo } \\
\end{array}$ & $\begin{array}{l}\text { Gerenciado e controlado } \\
\text { para maximizar lucros } \\
\text { sobre cultivo }\end{array}$ & $\begin{array}{l}\text { Cultivos de uma maneira } \\
\text { sustentável }\end{array}$ \\
\hline $\begin{array}{l}\text { Papel do } \\
\text { Estado }\end{array}$ & $\begin{array}{l}\text { Incentivo para } \\
\text { agricultura familiar }\end{array}$ & $\begin{array}{l}\text { Aporte para } \\
\text { agricultura produtiva } \\
\text { e processamento } \\
\text { alimentar }\end{array}$ & $\begin{array}{l}\text { Incentivo ao livre } \\
\text { comércio global e } \\
\text { regulação privada por } \\
\text { companhias de agro- } \\
\text { alimentos }\end{array}$ \\
\hline $\begin{array}{l}\text { Dinâmica } \\
\text { subjacente }\end{array}$ & $\begin{array}{l}\text { Disponibilidade de } \\
\text { produtos, aplicação } \\
\text { de tecnologias }\end{array}$ & $\begin{array}{l}\text { Disponibilidade e preço } \\
\text { de produtos, dominância } \\
\text { tecnológica }\end{array}$ & $\begin{array}{l}\text { 'Greening' de } \\
\text { consumidores, sociedade } \\
\text { de risco }\end{array}$ \\
\hline
\end{tabular}

Fonte: Burch e Lawrence (2005) 
As estratégias dos supermercados para manter este controle são diversas. Em relação aos consumidores podem ser mencionados os cartões de fidelidade e o fato de passarem a ser, eles próprios, uma marca (HARVEY et al, 2002, p.174); e em relação às cadeias de abastecimento, a assinatura de contratos de longo prazo que permitem aos supermercados manter preços baixos (COX et al, 2002).

A identificação desta nova fase no sistema alimentar vai ao encontro de questionamentos do paradigma convencional a) que separa produção/consumo e b) que se apóia na abordagem de cadeia de mercadorias. Em relação ao primeiro aspecto é fundamental entender o setor supermercadista mais que meramente como um elo dedicado à distribuição, assim como é importante entender melhor as difusas fronteiras entre produção e consumo. Isto implica um desafio de superar a dicotomia tradicional entre esses termos dentro dos debates sobre o sistema alimentar e evitar essencialismos nas suas definições.

Em relação ao segundo ponto, Lockie et al (2006) têm contribuído na identificação da terceira fase ao considerar que falar de "cadeias de mercadorias" simplifica demais as relações sociais e econômicas centradas no setor supermercadista, além de ser apontar a dinâmicas lineais e unidirecionais. O conceito proposto por esses autores é o de "circuito", que move o eixo da análise para a rede, sem claro início ou ponto final. Os circuitos envolvem

fluxos interconectados não só de produtos físicos, mas também de discursos, conhecimentos, imagens e símbolos. (...) [O] foco é colocado nas relações de poder na rede de forma a entender como os atores se organizam, não só em torno da produção e distribuição dos produtos agrícolas, mas também em torno da produção de sentido sobre preocupações como "qualidade", "saúde" e "seguridade" (LAWRENCE \& BURCH, 2007, p.11).

A presença crescentemente significativa dos supermercados no setor de alimentos verdes é parte de transformações induzidas pelos próprios supermercados na esfera do consumo alimentar, pela oferta de novas opções e tomada de iniciativas a respeito de inovações nos produtos e qualidade do alimento. Durante os anos 
90, uma mudança fundamental aconteceu no comércio a varejo nos países ocidentais: da venda de produtos alimentares de marca altamente padronizados e embalados para clientes leais, para estratégias cada vez mais fragmentadas de micro-marketing vendendo alimentos perecíveis como frutas, vegetais, lacticínios e carne. Os varejistas construíram os chamados regimes de interesse-privado ou baseados no mercado para o controle de qualidade, oferecendo ao consumidor escolha individual também com respeito à qualidade do alimento "além dos padrões básicos". Embora muitos governos ainda representem um importante papel na regulação de mercados alimentares, os varejistas estão "no ápice da construção dessa qualidade; sendo capazes de absorver e transmitir mudanças regulatórias, reações dos clientes e parâmetros de segurança para a qualidade na cadeia de suprimento" (MARSDEN et al. 2000, p.8).

Desta maneira, a centralidade do setor supermercadista vai ainda além dos pontos acima enumerados, estabelecendo iniciativas de significativa influência tanto entre provedores quanto consumidores no que diz respeito a tendências de consumo de alimentos saudáveis e, podemos agregar aqui, como veremos em detalhe mais adiante, práticas ambientais.

\section{Os supermercados à luz da modernização ecológica ${ }^{1}$ e da sociologia econômica dos objetos do mercado}

A análise da transformação do setor supermercadista no sistema alimentar seguindo a teoria da modernização ecológica nos permite identificar as principais pedras angulares da estrutura para a análise das práticas que envolvem os diversos atores da rede varejista. Ambas as características físicas do estabelecimento varejista e as relações sociais que governam as práticas de compra são o resultado de uma articulação específica das forças ou dinâmicas locais e globais. A distinção apresentada por Castells (1999) entre o espaço de lugar e o espaço de fluxos pode ajudar a compreender analiticamente estas dinâmicas, sem incorrer em um dualismo

1 Este item segue os argumentos de Oosterveer, Guivant e Spaargaren (2007). 
simplista. Estes conceitos são úteis apenas se não recairmos em uma interpretação deste esquema que situa as transições da sustentabilidade exclusiva ou primariamente na "dinâmica local" do espaço de lugar, enquanto as forças globais e a dinâmica do espaço de fluxos são reconhecidas como uma ameaça e um fator negativo para as transições da sustentabilidade (OOSTERVER, 2006). Uma dimensão estimulante das transições da sustentabilidade no setor alimentar acontece, por exemplo, quando testemunhamos a globalização e padronização dos modos de produção e consumo de alimentos orgânicos anteriormente restritos a nichos de mercado. Essas heterodoxias podem apenas ser entendidas e propriamente analisadas quando possibilidades para uma mudança ambiental no plano do espaço de fluxos forem também levadas em conta e analisadas com respeito aos muitos modos divergentes de se estar conectado à dinâmica e fatores locais no espaço de lugar.

\subsection{O ponto de venda como local para transações de alimentos sustentáveis e conversão de consumidores}

Seguindo uma ótica etnográfica e a metáfora do jardim, mencionada na introdução, o ponto de venda constitui o local onde as cadeias de supermercados e consumidores interagem na venda e compra de alimentos sustentáveis, ou onde estratégias de fornecedor e consumidor de fato se encontram. Embora as práticas sociais no estabelecimento varejista não possam ser entendidas sem incluir as diferentes estratégias apresentadas acima, até agora, muito pouca pesquisa empírica tem sido feita aplicando esta perspectiva.

Todavia, alguns achados empíricos estão disponíveis e um ponto de partida interessante é a configuração física da loja. O modo em que produtos alimentares sustentáveis são posicionados no cenário da loja dá provas de ser muito importante no sucesso de tais produtos. Itens como o sortimento de produtos alimentares sustentáveis (quantitativo e qualitativo), o posicionamento do sortimento verde no sortimento geral, a estrutura espacial da provisão verde e a dimensão da sustentabilidade referida são di- 
ferenças características no estabelecimento e por isso facilitam ou complicam a execução de determinadas estratégias de fornecedores e consumidores (BARREY, 2007).

Os supermercados podem usar diferentes estratégias em suas lojas ao comercializar produtos orgânicos. Algumas diferenças essenciais que caracterizam estas estratégias são o número e diversidade de produtos no estabelecimento varejista, a motivação e qualificação dos trabalhadores no ponto de venda e a apresentação e posicionamento dos produtos na loja.

No caso brasileiro, a demanda por alimentos saudáveis está contribuindo significativamente para o crescimento da produção e consumo de orgânicos, contradizendo as previsões negativas de uma parte do movimento da agricultura orgânica sobre vendas por meio de supermercados. Pode-se esperar que esta estratégia de provisão a partir do setor varejista esteja "convertendo" consumidores a se tornarem mais "verdes" (GUIVANT, 2003; MORO, 2009).

Se os consumidores engajam-se ou não nas transições da sustentabilidade no setor de alimentos, depende de diferentes fatores, alguns dos quais são mais fáceis de detectar e analisar do que outros. Uma ocasião interessante para estudar este fenômeno é no estabelecimento varejista, onde podemos abordar consumidores e suas práticas de compra enquanto se estabelece um balanço entre abordagens micro e macro.

Primeiro, há o plano visual ligado aos produtos e serviços mais sustentáveis em oferta, isto é, o modo em que estes produtos são apresentados ao consumidor, tanto quanto os sistemas de informação vinculados a eles. Indicadores visuais são importantes para analisar consumidores emergentes comprando alimentos sustentáveis, mas a fim de realmente ter um entendimento em profundidade das práticas de consumo implicadas na compra de alimentos sustentáveis em estabelecimentos varejistas, estes artifícios físicos são apenas um primeiro passo. Para as informações, imagens, mensagens, produtos e serviços serem realmente aceitos, comprados ou "apropriados" pelos cidadãos-consumidores, eles têm que estar encaixados em um sistema vital e ativo de relações de confiança que envolve provedores e cidadãos-consumidores. 
Quando aplicadas ao nosso objeto de análise, os estabelecimentos varejistas, estas hipóteses ajudam a "ler a partir das prateleiras" que tipos de relações sociais e estratégias são refletidas e espelhadas no cenário físico específico do estabelecimento varejista. Estas noções de confiança e relações de poder "sendo espelhadas" ou "refletidas" em características físicas do cenário não deveriam ser interpretadas de um modo estático ou mecânico. Para sermos capazes de ler e decifrar estas relações de confiança inscritas foi preciso uma teoria social sobre os modos em que as relações por trás do produto e dos fluxos de informação são organizadas no contexto da modernidade reflexiva. Na linguagem da teoria da estruturação, estas relações de poder e confiança são consideradas como instantâneas no momento em que as pessoas realizam a prática social de compra.

Quando um conjunto de indicadores válidos para avaliações no plano da loja está disponível, eles podem ser usados não apenas para avaliar políticas ambientais, mas também para a avaliação e construção das formas de envolvimento da cidadania baseada no mercado no "enverdecimento" das cadeias alimentares. Imagens de produto e troca de informação sobre as circunstâncias da produção de certos alimentos fornecidas por ONGs, mídia pública ou Internet e comunicação via e-mail, em combinação com as políticas internas dos supermercados para informação e comunicação, podem influenciar as práticas de compra dos consumidores. Micheletti (2003) refere-se a formas particulares de engajamento em termos de "consumo político", e ela mostra que conjuntos confiáveis de indicadores de performance ambiental no plano do varejo podem ser usados para muitas formas de ação e pressão ambiental. As relações de poder igualmente tomam características específicas no estabelecimento varejista. Ao complementar as noções mais convencionais de poder econômico dos produtores e consumidores de alimentos, o poder político dentro do estabelecimento e o controle da informação adquirem crescente importância. Vistas desta perspectiva, as práticas de compra são diretamente ligadas às decisões dos supermercados sobre como organizar o abastecimento de alimentos em suas lojas. 


\subsection{Estratégias de responsabilidade ambiental}

A ampliação das estratégias de responsabilidade ambiental visando um modelo de sustentabilidade pode ser observada em diversas práticas e iniciativas do setor supermercadista no mundo. Focalizando no caso do Brasil, podem ser incluídas as seguintes iniciativas:

1) parceria entre o Wal-Mart e o Instituto Akatu desde 2008 para realizar um trabalho de sustentabilidade envolvendo todas as suas unidades, de várias bandeiras. O Instituto Akatu coordena um processo de educação dos cerca de 60 mil associados da rede de supermercados sobre o conceito do Consumo Consciente. O trabalho desenvolvido pelo Wal-Mart possui dez "frentes" de ação, denominadas "plataformas". A nona frente chama-se "Associados Conscientes" e é onde se encaixa o trabalho de capacitação realizado pelo Akatu. O projeto está em sua fase piloto e engloba sete unidades da rede Wal-Mart. No total, nesta primeira etapa, o Akatu vai capacitar diretamente cerca de 150 pessoas. São os chamados multiplicadores, grupo formado por funcionários de diferentes hierarquias que, em seguida, passarão os conceitos e práticas apreendidos para os demais colegas.

2) Em 2005, a rede Pão de Açúcar assumiu no seu discurso o conceito do triple bottom line, e suas ações assumiram como objetivo a competitividade e lucratividade ao mesmo tempo em que possam contribuir com a melhoria dos processos da cadeia de varejo e na construção de uma sociedade mais justa e sustentável. A companhia investe em projetos sócio-ambientais e de consumo responsável de longo prazo. Somente neste ano, serão aplicados R\$ 18 milhões em ações relacionadas às causas protagonizadas pela empresa: sustentabilidade no consumo, desenvolvimento comunitário e bem estar pessoal. Entre os principais programas realizados pela empresa, destaca-se o de reciclagem. Um dos pilares da abordagem ecologicamente correta da Companhia é a reciclagem do lixo. Além de práticas para minimizar o 
impacto do seu negócio, a empresa volta seus esforços para a conscientização da importância do tema a todos os seus públicos. O Projeto "Estações de Reciclagem Pão de Açúcar Unilever" já recebeu, desde o seu lançamento, em 2001, dezessete mil toneladas de material, incluindo plásticos, papéis, metais, alumínios e vidros. Por mês, somados os 91 pontos de coleta, o programa recebe, em média, 400 toneladas de resíduos. O projeto, além de proteger o meio ambiente, gera 350 posições de trabalho como atendentes, coletores e triadores de materiais, que fazem parte de 19 cooperativas de catadores. Para complementar, o sistema proposto pelas Estações de Reciclagem Pão de Açúcar Unilever é incentivar os consumidores a reciclar, as lojas da rede distribuem sacolas de supermercados com estampas nas cores padrão de reciclagem e informações sobre o processo de separação dos materiais. Além disso, orientadores ambientais (fiscais da natureza) supervisionam cada uma das estações e estimulam os clientes a participarem do projeto separando o seu lixo doméstico e trazendo para a estação.

3) Diversas iniciativas ligadas ao uso de sacolas retornáveis, a partir de legislações estaduais obrigando seu uso.

3.1. A Plastivida Instituto Sócio-Ambiental dos Plásticos, o Instituto Nacional do Plástico (INP) e a Associação Brasileira da Indústria de Embalagens Flexíveis (Abief) mantêm um Compromisso de Parceria para a Implementação do Programa de Qualidade e Consumo Responsável de Sacolas Plásticas, que visa a reduzir o consumo da embalagem no Brasil em no mínimo 30\%. A iniciativa é resultado de uma parceria dos representantes da indústria do plástico com a Associação Brasileira de Supermercados (Abras) e com a Associação Paulista de Supermercados (Apas). As cinco entidades assumiram formalmente, diante do vice-presidente José Alencar, do governador José Serra e do prefeito Gilberto Kassab, na cerimônia de abertura da Apas 2008 - 24ํㅡㄹ Congresso de Gestão e Feira Internacional de Negócios em Supermercados, o compromisso 
de estimular o consumo responsável no país. O evento é o mais importante do setor na América Latina e, nesse ano, esteve voltado inteiramente ao debate da sustentabilidade no consumo.

3.2. Produzidas de acordo com a norma ABNT 14.937, as sacolinhas ficam mais resistentes e trazem estampado o peso que suportam, oferecendo segurança ao consumidor, que pode dispensar a sobreposição da embalagem e usá-la em sua capacidade total. De acordo com simulações já realizadas pela Plastivida, com isso, é possível reduzir em pelo menos um terço a distribuição das sacolinhas nos supermercados.

O projeto piloto, que foi instalado em 18 lojas da Grande São Paulo - 14 das redes Pão de Açúcar e Carrefour e 4 de outras bandeiras - e depois espalhado para o restante do país, prevê ainda ações de educação para conscientizar os consumidores a usar apenas o número de embalagens efetivamente necessário para transportar as compras.

Uma pesquisa realizada pelo Ibope no fim do ano passado com 600 pessoas mostrou que nada menos do que $71 \%$ delas manifestaram-se favoráveis ao uso de sacolinhas plásticas como a forma ideal para o transporte de compras. Revelou ainda que $100 \%$ usam as embalagens para o descarte do lixo doméstico, dispensando a compra de sacos para esse fim. O Pão de Açúcar foi a primeira varejista a introduzir programas para redução do uso de embalagens descartáveis, em 2005. Desde então, a rede investe continuamente em novas alternativas que melhor atendam as necessidades e diferentes perfis de clientes que frequientam as suas lojas. Já são 12 diferentes modelos de ecobags que vão desde as de TNT, com renda revertida para a Fundação SOS Mata Atlântica, até as que vão acopladas aos carrinhos de compras ${ }^{2}$.

2 Este processo pode ser observado em outros países. A TetraPak, especialista em sistemas para processamento, envase, e distribuição de embalagens longa vida, e as Sainsbury's, empresa varejista do setor alimentício do Reino Unidos, anun- 
Além deste tipo de selo, diversas redes internacionais de supermercados estão começando a utilizar os selos com dados da pegada de emissão de carbono nos rótulos de alimentos. No Brasil trata-se de uma iniciativa incipiente. Depois de redes de supermercados britânicas criaram selos com informações sobre a pegada de emissão de carbono para serem exibidos nos produtos que vendem, o Japão decidiu que esta seria uma boa tática para motivar a população a colaborar com os planos ambiciosos do governo no combate ao aquecimento global. A proprietária de supermercados Aeon está entre as companhias que devem aderir aos selos.

\subsection{Modelos de gestão e construção sustentável}

A Revista Superhiper, da Associação Brasileira de Supermercados, dedicou o número de fevereiro de 2009 ao tema da construção de lojas sobre os pilares da sustentabilidade. A definição dada para um supermercado sustentável é a de um "estabelecimento que se preocupa com a saúde dos colaboradores e dos clientes e com a qualidade de vida da população que o cerca, buscando se relacionar com os núcleos carentes que vivem nas imediações. Além disso, procura causar o menor impacto ambiental Possível na região onde está ou será instalado" (SUPERHIPER, fevereiro 2009, p.31).

Entre as justificativas apresentadas para este tipo de empreendimento, está o argumento de que "a adoção de práticas sustentáveis é a principal tendência de construção para as redes supermercadistas, que em pouco tempo precisarão implantar medidas socioambientais para acompanhar o mercado e não perder espaço

ciaram o lançamento da primeira embalagem mundial com o selo de certificação do Forest Stewardship Council (FSC), organização que estabelece padrões para gerenciamento responsável das florestas. Trata-se da Tetra Recart, embalagem longa vida que preserva alimentos sólidos sem necessidade de refrigeração ou adição de conservantes. Segundo o fabricante, ela é firme, não quebra e não corta, assegurando maior segurança para o consumidor. A Sainsbury's é a primeira rede de supermercados do mundo a ter em estoque a embalagem Tetra Recart, produzida com fibra de madeira certificada pela FSC. O sistema de certificação garante uma cadeia de custódia desde a floresta até os pontos de venda. 
para a concorrência." Sem dúvida reconhece-se que as mudanças na direção da sustentabilidade envolverão altos custos, mas o editor da publicação garante que "as empresas economizarão mais à frente e terão ganhos não só financeiros, mas de durabilidade e consistência de seus negócios". O marketing corporativo seria um dos pontos de vantagem, colocando a empresa num novo posicionamento no mercado, frente aos consumidores e à indústria. O outro é a recuperação rápida de gastos com a economia de custos operacionais.

A preocupação com o desempenho ambiental de prédios é parte de uma tendência global crescente, que passa pelas formas de construção, operação e até demolição. Como afirmam Presas e Mol (2006, p.303), “o uso de energia, o consumo de água, os materiais de construção, o manejo do lixo, questões de transporte, e condições de trabalho dentro dos prédios, como qualidade do ar...são só alguns dos temas ambientais que regularmente emergem nos debates sobre as iniciativas públicas e privadas...". De acordo com estes autores, num estudo sobre a transformação ambiental em prédios de transnacionais, tal tendência deve ser entendida a partir das interseções entre o global e o local. Isto é, as práticas desenvolvidas pelas empresas e instituições globais em cruzamento com as infra-estruturas e interesses locais e nacionais oferecem o marco para entender as transformações ambientais na construção dos supermercados.

As redes Tesco e Sainsbury, duas das maiores do Reino Unido, investem em medidas de redução de energia, uso de materiais recicláveis e geração elétrica a partir do lixo para reduzirem emissões de $\mathrm{CO} 2$. Primeiro veio a substituição de sacolas plásticas por reutilizáveis, depois o uso de fontes renováveis seguido pela criação de rótulos com informações sobre as emissões de carbono de cada produto. Agora, os supermercados britânicos planejam transformar o lixo em biocombustível e reduzir em até $70 \%$ as emissões de gases do efeito estufa.

O Tesco, terceiro maior varejista do mundo, inaugurou recentemente a sua primeira loja com baixas emissões de carbono, que produz $70 \%$ menos gases do efeito estufa que aquelas construídas há apenas dois anos. Telhados que possibilitam a entrada de luz natural e outras ações de eficiência energética resultaram na redução de $31 \%$ nas emissões. O uso de dióxido de carbono (CO2) como gás de 
refrigeração em vez de HFCs ajudou a reduzir outros $21 \%$. E a utilização de uma usina de energia e calor alimentado por óleos vegetais reciclados permitiu a loja gerar sua própria energia e usar o calor desperdiçado, assim como diminuir mais $19 \%$ das emissões totais. A nova loja faz parte do plano da empresa de cortar pela metade as emissões de CO2 de todas as lojas que forem construídas até 2020, comparando com uma equivalente construída em 2006.

As medidas adotadas incluem a substituição das prateleiras de ferro por feitas de madeira; o aumento do uso de materiais recicláveis nas instalações fixas, nos painéis de anúncios e nas peças decorativas para facilitar a reciclagem no futuro; a instalação de sistemas de medição para monitorar o uso de água e energia, e o controle para evitar, o máximo possível, a geração de lixo no processo de construção, com a reutilização dos materiais não usados.

A pró-atividade do Tesco em relação à questão climática não é exceção no Reino Unido. As concorrentes também investem em ações para reduzir as emissões de gases do efeito estufa, como a rede Sainsbury, que na última semana anunciou que até setembro todas as lojas do país irão transformar os alimentos que antes iriam para o lixo em energia elétrica. Até o final de fevereiro, as 28 lojas da Escócia já terão as 42 toneladas de lixo orgânico que produzem semanalmente enviadas para uma refinaria de biocombustível.

Voltando a matéria da revista Superhiper, mencionada acima, as recomendações para o setor envolvem desde sugestões sobre os materiais que se pretende usar na construção, fazer uso de componentes produzidos em fornecedores próximos e seguir uma série de etapas importantes no processo construtivo. A revista cita o caso do Grupo Pão de Açúcar, com uma loja em Indaiatuba (São Paulo), que seguiu diversas estratégias sustentáveis na sua construção. A unidade, batizada pelo grupo como "loja verde", foi adequada aos requisitos do sistema Leed (Leadership in Energy and Environmental Design), formulados pelo United States Green Building Council - órgão que certifica construções sustentáveis. Esta certificação custa em torno de $2 \%$ do projeto.

Outro exemplo no país é o da rede Wal-Mart, a terceira maior no Brasil, que utilizou diversas diretrizes de sustentabilidade na construção de sua loja no bairro de Campinho, na zona norte de Rio de 
Janeiro. Com esta iniciativa a rede pretende reduzir em aproximadamente $40 \%$ o uso de água e em $25 \%$ o consumo de energia elétrica.

Os casos estendem-se a pequenas e médias redes. A rede Lopes, com 15 lojas em São Paulo, abriu sua mais nova loja, na cidade de Carapicuíba, com um mecanismo de climatização que substitui os aparelhos de ar condicionado. As redes Peluzzo, do Rio Grande do Sul, e Oba, em São Paulo, Minas Gerais e Distrito Federal, estão entre as que adotaram sistemas de reaproveitamento de água das chuvas para usos diversos. A rede mineira SuperNosso, com 11 lojas, investiu em 2008 25\% a mais na construção da "loja verde" em Belo Horizonte. Entre os equipamentos, estão os projetados para eliminar o uso de equipamentos de ar condicionado e a transformação na refrigeração.

Esta última medida é uma das mais utilizadas nos exemplos mencionados, envolvendo a gestão dos gases utilizados normalmente nos refrigeradores de supermercados (os CFCs). Estes colaboram 1.780 vezes mais para o aquecimento global do que as substâncias recomendadas pelo ministério, segundo a Associação Brasileira de Refrigeração, Ar-Condicionado, Ventilação e Aquecimento (ABRAVA). A cada ano mais de $80 \%$ de gases de refrigeradores de supermercados brasileiros vazam para a atmosfera devido à má conservação ou problemas na hora do conserto. Em geral, os supermercados utilizam freezers e geladeiras com gases HCFC (hidroclorofluorcarbono) e CFC (clorofluorcarbono), que contribuem para aumentar o efeito estufa.

O processo de construção de uma loja sustentável estimula uma dinâmica criativa e inovadora, com cada rede assumindo estratégias que mantêm especificidades locais e regionais, dentro de políticas que podem ser de caráter nacional e/ou global, dependendo da rede em questão.

\section{A perspectiva dos consumidores e das ONGs}

É evidente que ambientalistas, representantes de Organizações Não Governamentais (ONGs) e políticos têm questionado significativamente as políticas e discursos ambientais dos supermercados (LASZLO, 2008). 
No Brasil diversas pesquisas apontam a preocupações de consumidores sobre o desempenho social e ambiental das empresas. A "Pesquisa 2006 e 2007 - Responsabilidade Social Empresarial Percepção do Consumidor Brasileiro", lançada em 26 de março de 2008 pelos Institutos Akatu e Ethos, realizada pela Market Analysis Brasil, e cuja publicação foi patrocinada pelo Carrefour, indica que $77 \%$ dos brasileiros têm interesse em saber como as empresas tentam ser socialmente responsáveis, revelando estabilidade na comparação com os índices obtidos nas pesquisas anteriores. Além disso, dois em cada três brasileiros têm uma avaliação positiva sobre a contribuição das grandes empresas para o desenvolvimento da sociedade. A porcentagem de entrevistados que se encaixaram nesta categoria em 2007 (66,5\%) sofreu um acréscimo de dez pontos percentuais em relação a 2006 (57\%).

O número de brasileiros que sabem que têm o poder de influenciar o comportamento das empresas (75\%) se manteve relativamente estável desde 2002 até 2007 , porém o consumidor não é ativo na mesma proporção em termos de buscar informações sobre o comportamento das empresas. Atualmente, apenas um em cada três consumidores consultados afirma procurar saber mais sobre o comportamento das empresas. Não é pouco, mas está distante do número de pessoas que declara acreditar no poder do consumidor de influenciar as empresas.

Um dado que chamou a atenção é o aumento do número de entrevistados que acreditam que o governo deve criar leis para obrigar as grandes companhias a irem além do seu papel tradicional e contribuírem para uma sociedade melhor, mesmo que isso cause preços maiores e redução no número de empregos. O percentual de consumidores que manifestaram essa opinião passou de $57 \%$ em 2004 para 64\% em 2006.

Entretanto, como é comum neste tipo de pesquisa de opinião pública os resultados podem indicar diversos caminhos da consciência sustentável. Uma pesquisa realizada pela TNS InterScience em 2008 no Brasil mostra que $51 \%$ dos brasileiros compram produtos ecologicamente corretos, como alimentos orgânicos, artigos que possuam embalagens recicláveis, móveis feitos com madeira certi- 
ficada, eletrodomésticos que consomem menos energia e roupas confeccionadas com tecidos naturais. Outros $23 \%$ disseram que ainda não compram, mas pretendem comprar esses produtos. Segundo o levantamento, a influência do meio ambiente na decisão de compra engloba veículos, produtos de saúde, alimentos, produtos para casa e viagens. Para $52 \%$ dos entrevistados, o meio ambiente tem muita influência na decisão da compra. E $83 \%$ afirmam que aceitariam pagar mais por produtos ecológicos. A pesquisa também procurou descobrir o perfil do consumidor ecologicamente correto. $\mathrm{Na}$ opinião do consultor Mario Cunha, professor da FAAP, são pessoas críticas, jovens, bem informados e menos resistentes à mudanças. Para 26\%, pensar no meio ambiente é a coisa certa a se fazer na hora da compra. Outros $25 \%$ dizem que o "status" impulsiona o consumo e 23\% acham que eles são mais baratos (www.metropoint.com).

Globalmente, um dos alvos mais atacados entre o setor supermercadista tem sido o Wal-Mart incluindo-se o filme "The high cost of low price". As diversas e fortes criticas (desde poluição a péssimas políticas de emprego) produziram efeitos significativos, como manchar a própria reputação da companhia o que teria influenciado na queda do valor das ações em 20\% entre 2000 e 2005. Este quadro levou a diretoria a considerar mudanças radicais na forma de organização, gestão e publicidade da rede. De acordo com uma nota no Jornal New York Times (24 de Janeiro de 2009), teve lugar em Arkansas, em 2005, uma conferência secreta de dois dias, na qual Lee Scott, presidente mundial da rede, teria afirmado a necessidade de assumir uma estratégia de sustentabilidade ambiental para atingir dois objetivos: melhorar a eficiência e a reputação. A escolha era adotar um programa de sustentabilidade que refizesse o perfil de toda a companhia, incluindo objetivos de longo prazo como só utilizar energia renovável, criar lixo zero e vender produtos que sejam sustentáveis.

Isto levou a Wal-Mart a pressionar seus fornecedores, como General Electric eProcter \& Gamble a transformar suas próprias práticas produtivas (mostrando assim que a fase 3 do sistema alimentar, com o papel central dos supermercados, estende-se além do setor propriamente alimentar). $\mathrm{O}$ efeito-cascata poder ser avaliado atualmente, segundo a mesma nota do New York Times, pelos mais dos 
200 milhões de consumidores de Wal-Mart que compram lâmpadas fluorescentes, que usam menos de $75 \%$ de eletricidade que as lâmpadas incandescentes. Os dados de 2007 apontam que a Wal-Mart vendeu mais de 100 milhões destas lâmpadas. Isto, obviamente, não significa maiores lucros para os fabricantes, porque lâmpadas que duram mais levam a vender menos. Mas perder a Wal-Mart como cliente seria um custo maior para as empresas do setor.

A lista de produtos nessa situação é extensa, incluindo detergente concentrado que usa $50 \%$ menos de água e medicamentos que usam $50 \%$ menos de embalagem. A venda de alimentos orgânicos passou a ser outra das bandeiras da rede. A partir de 2006, a Wal-Mart decidiu passar a oferecer alimentos orgânicos com um plus de $10 \%$ sobre os alimentos convencionais. Junto com as vantagens que pode significar trazer alimentos orgânicos para milhões de consumidores a um preço acessível, as criticas não diminuíram. Como se imagina que a rede gigante não vai comprar de pequenos produtores locais, a influência no mercado seria a de favorecer grandes produtores, mecanizados e com um sistema de processamento e transporte que não seria diferente da produção convencional de alimentos (POLLAN, 2006)

As ambigüidades desta política aparecem facilmente. Durante um evento promovido em março de 2008 pelo jornal The Wall Street Journal nos Estados Unidos, Lee Scott deixou clara sua posição: "Não somos verdes". Ele acrescentou que "sua saga rumo à sustentabilidade ambiental e social é motivada menos pela vontade de conquistar o respeito dos ambientalistas e mais pela gana de economizar dinheiro" - afirmação, que, obviamente, não provocou nenhuma simpatia nas ONGs." (REVISTA EXAME, 20/03/2008)

Os questionamentos não deixam de lado outras redes, como a Tesco, terceira maior varejista do mundo. A Consumers International (CI) anunciou em 01/12/2008, entre os "vencedores" do Prêmio Piores Empresas 2008, a rede Tesco. O Bad Company Awards destaca algumas das principais marcas mundiais por comportamentos irresponsáveis nos últimos 12 meses. A campanha tem como objetivo chamar atenção para os direitos dos consumidores. A intenção é ressaltar a necessidade de fiscalização e esclarecimento sobre os 
direitos dos cidadãos nas relações de consumo. A Tesco recebeu o Prêmio "Marreta" por silenciar críticas. A empresa está processando três jornalistas tailandeses que criticaram as táticas de expansão da varejista na Ásia. A rede Tesco está exigindo mais de 34 milhões de dólares de indenização dos jornalistas que expuseram o grande impacto que o crescimento da companhia está causando aos negócios locais e aos consumidores. A expansão da Tesco na Ásia tem ocorrido de forma rápida e determinada. Em 2007, cerca de 21\% de seu lucro foi proveniente do continente e 106 lojas foram abertas na Tailândia. A crítica feita pelos três jornalistas não é incomum. Wal-Mart, Carrefour e a própria Tesco há anos têm sido questionados sobre suas atividades em diversos países por conta dos impactos causados aos comércios locais, nos salário dos trabalhadores e na redução das opções de compra para os consumidores.

\section{Comentários finais}

Neste artigo mostramos os diversos tipos de envolvimento dos supermercados em práticas que podem ser identificadas como sustentáveis. Obviamente o conceito de sustentabilidade é suficientemente amplo como para abranger estratégias que visem desde o estimulo ao consumo verde até padrões de construção eco-eficiente. Mas, com estas iniciativas, ficam ainda mais fluidas as divisões entre os espaços alternativos e convencionais (HUGHES, 2007). Estes fluxos abrem novos desafios para a conceituação desses espaços em transformação. Para alguns autores trata-se de um desvirtuamento do espaço alternativo (POLLAN, 2008), enquanto para outros, a partir da teoria da modernização ecológica, podem ser identificadas relações complexas e móveis entre o que pode ser alternativo e convencional.

O quadro aqui mostrado expõe um mosaico complexo que exige uma perspectiva não essencialista ou dicotômica para entender como as dinâmicas e demandas ambientais passam a fazer parte não só do discurso, mas de práticas influentes de atores econômicos poderosos e que podem passar a ter consequiências não-premeditadas nas relações entre produção e consumo nas 
novas regras da globalização dos mercados. E neste aspecto, uma significativa contribuição para ser mais desenvolvida é a apresentada pela sociologia econômica dos objetos de mercado.

\section{Referências}

BARREY, S. Struggling to be displayed at the point of purchase: the emergence of merchandising in French Supermarkets. In: CALLON, M., MILLO, Y. \& MUNIESA, E.F. (Eds.), Market Devices. Londres: Blackwell, 2007.

BECK, U. \& SZNAIDER, N. Unpacking cosmopolitanism for the social sciences: a research agenda. The British Journal of Sociology. Volume 57, Issue 1, 2006

BEVAN, J. Trolley wars. The battle of the supermarkets. Londres: Profile, 2005.

BURCH, D. \& LAWRENCE, G. Supermarket own Brands, supply Chains and the transformation of the agri-food System. In: International Journal Of Sociology Of Agriculture And Food, Volume 13, Number 1, July, 2005.

CASTELLS, M. La era de la información. El poder de la identidad. Vol.2. México: ed. S.XXI, 1999.

COCHOY, F. A sociology of market-things: on tending the garden of choices in mass retailing. In: CALLON, M.; MILLO, Y. \& MUNIESA, E.F. (Eds.). Market Devices. Londres: Blackwell, 2007.

COX, A; IRELAND, P.; LONSDALE, C., SANDERSON, J. \& WATSON, G. Supply Chains, Markets And Power: Mapping Buyer And Supplier Power Regimes. London: Routledge, 2002.

DIXON, J. Authority, Power And Value In Contemporary Industrial Food Systems. International Journal Of Sociology Of Agriculture And Food, 11, 1, 2003.

DOBSON, P.W.; WATERSON, M. \& DAVIES, S.W. The patterns and implications of increasing concentration in European food retailing. Journal of Agricultural Economics, 54, 2003. 
GUIVANT, J. S. Os supermercados na oferta de alimentos orgânicos: apelando ao estilo de vida egotrip. In: Ambiente \& sociedade, Campinas, Unicamp, v. VI, n. 2, p. 63-82, 2003.

HARVEY, M.; QUILLEY, S. \& BEYNON, H. Exploring the Tomato: Transformations of Nature, Society and Economy. Cheltenham: Edward Elgar, 2002.

HUGHES, A. Supermarkets and the ethical/fairtrade movement: making spaces for alternatives in mainstream economies?. In: Burch, D. and G. Lawrence (Eds.), Supermarkets and Agri-food supply chains. Transformations in the production and consumption of foods. Massachusetts: Edward Elgar, 2007.

LASZLO, C. Valor sustentável. São Paulo: Qualitymark, 2008.

LAWRENCE, G. \& BURCH, D. Undestanding supermarkets and agri-food supply chains. In: BURCH, D. \& LAWRENCE, G. (Eds.). Supermarkets and agri-food supply Chains. Transformations in the production and consumption of foods. Massachusetts: Edward Elgar, 2007.

LOCKIE, S.; LYONS, K.; LAWRENCE, G. \& HALPIN, D. Going organic: Mobilizing networks for environmentally responsible food production. Wallingford, UK: CAB International, 2006.

MARSDEN, T.; FLYNN, A. \& HARRISON, M. Consuming Interests: The social Provision of Foods. London: UCL, 2000.

MCMICHAEL, P. \& FRIEDMANN, H. Situating the 'Retailing Revolution'. In: BURCH, D. \& LAWRENCE, G. (Eds). Supermarkets and Agri-food supply chains. Transformations in the production and consumption of foods. Massachusetts: Edward Elgar, 2007.

MICHELETE, M. Political Virtue and Shopping: Individuals, Consumerism, and Collective Action. New York: Palgrave Macmillan, 2003.

MORO, E. A relevância sociológica das estratégias das redes de supermercados para os alimentos orgânicos. Artigo apresentado no XIV Congresso Brasileiro de Sociologia. Rio de Janeiro, 2009.

OOSTERVEER, P. Environmental governance of global food flows: the case of labeling strategies. In: SPAARGAREN, G.; MOL, A. \& BUTTEL, F. (Eds.). Governing environmental flows. Global challenges to social theory. Cambridge: MIT, 2006. 
OOSTERVEeR, P., GUIVANT, J.S. \& SPARGAAREN, G.. Green Consumption in Globalizing Food Markets. In: PRETTY, J.; GUIVANTE, J.; BENTON, T.; LEE, D.; ORR, D. \& WARD, H. (Org.). The Sage Handbook on Environment and Society. London: Sage, 2007.

POLLAN, M. Wal-Mart goes organic: and now for the bad News, 2006. http://pollan.blogs.nytimes.com/2006/05/15/wal-mart-goesorganic-and-now-for-the-bad-news.

. Em defesa da comida. Um manifesto. Rio de Janeiro: Intrínseca, 2008.

PRESAS, L. \& MOL, A. Greening transnational buildings: between global flows and local places. In: SPAARGAREN, G. MOL, A. \& BUTTEL, F. (Eds), Governing environmental Flows. Global Challenges to social Theory. Cambridge: MIT, 2006.

. (Eds.) Environment and global modernity. Londres: Sage, 2000.

. (Eds.) Governing environmental flows. Global challenges to social theory. Cambridge: MIT, 2006.

REYNOLDS, J. \& CUTHBERSTON, C. (Eds.) Retail Strategy. The view from the bridge. Oxford: Elsevier Butterworth-Heinemann, 2004.

SETH, A. \& RANDALL, G. The grocers. The rise and rise of the supermarket chains. Londres: Kogan Page, 2001.

\begin{abstract}
Market control through eco-efficiency and eco-consumption: an analysis based on supermarkets.

This article begins with a discussion of the changing role of supermarkets in the food system. According to some authors, the system itself has now entered its third stage. Among the numerous transformations that are a part of this process, we give particular salience to two: a) the role of supermarkets in turning consumers into consumers of organic foods and produce and $b$ ) the strategies of the supermarket sector in sustainable management and construction. Sustainability has become an increasingly central motif in the supermarket sector's strategies, something that has evidently become possible due to the imprecise nature of the concept. Our analysis is fundamentally based on the theory of ecological modernization and secondarily on the new economic sociology of market objects. Through
\end{abstract}


this theoretical framework, we are able to illustrate retail sector tendencies in global market flux, as well as the influence of non-governmental organization and consumer group action. Lastly, we reveal the complex mosaic of the sector's tendencies. A non-dichotomous and non-essentialist perspective is required in order to understand how environmental dynamics and demands come to form part not only of the discourse but of influential practices of these powerful economic actors which may have unintended consequences on relationships between production and consumption within the new rules of the globalization of markets.

Keywords: sustainable consumption, supermarkets, theory of ecological modernization. 